\title{
Development of a Prototype for Early Identification Children with Specific Learning Disabilities
}

\author{
Rosmayati Mohemad, Nur Fadila Akma Mamat, Noor Maizura Mohamad Noor, Arifah Che Alhadi
}

\begin{abstract}
Early identification of children who may at risk of having difficulties in learning is crucial in order to assist them in overcoming barriers to learn. The adoption of computer related information technology has been greatly explored to support specific learning disabilities children. However, current computer-based support systems are lacking to guide parents and teachers with information about the children with the specific learning disabilities. The early awareness of learning disabilities problems will help the parents and teachers to take suitable action for their children's academic and social development. Thus in this paper, a computer-based prototype for early identification children with specific learning disabilities using ontology (e-SLD) is developed and evaluated in terms of its usability based on Unified Theory of Acceptance and Use of Technology (UTAUT) factors. The research methodology consists of two main phases including software development life cycle and usability testing. The findings shows positive feedbacks of the prototype in terms of its usability, in which the average of $70 \%$ of the respondents agreed with the system's performance expectancy, $72 \%$ of the respondents agreed with the system in terms of its effort expectancy, 68\% of the respondents agreed with the system in terms of its social influence and around $72 \%$ of the respondents agreed that e-SLD is a tool to screening and recommending suitable activity of specific learning disabilities children.
\end{abstract}

Index Terms-Computer-based; Prototype Development; Screening; Specific Learning Disabilities.

\section{INTRODUCTION}

Education is one of the fundamental factors for a national development and economic growth, thus playing a vital role in developing a country. Despite of various traditional educational programs, the adoption of new technologies especially with the emerging of computer related information technology is beneficial to improve teaching and learning process, hence helping children develop to their full potential [1]-[3].
Nevertheless, children with difficulties in academic, emotional, social, visual-spatial and behavioural are unable to accommodate with the standard educational programs. These children are called special children as they require special support which is suitable for them, especially in education. Based on Individuals with Disabilities Education Act (IDEA), special education is divided in thirteen categories; autism, intellectual disability, traumatic brain injury, speech or language impairment, deaf-blindness, specific learning disability, deafness, emotional disturbance, hearing impairment, orthopedic impairment, visual impairment, multiple disabilities and other health impairment [4].

Specific learning disability is the academic problem, which is the focus in this research and it includes three types of disabilities such as such as dyslexia, dysgraphia and dyscalculia. These are the most frequently occurring disabilities among school-age students [5], [6]. For instance, the total number of Malaysian children with learning disability as shown in Figure 1 is increasing every year (Ministry Education of Malaysia, 2016). Various critical issues in this domain have been continuously discussed among researchers. One of the issues is the lack of awareness and knowledge among communities and parents that leads to a negative attitude in accepting limitations in the potential of special children and unawareness about the significance of special education for such children [7]-[9]. In addition, the lack of knowledge also creates misunderstanding among parents and practitioners in deciding on appropriate diagnosis and treatment for their children with learning disabilities [10][11]. Thus, parents need supports and practical guidelines on in-home practices in order to assist their struggling child in the learning process. These children actually have the abilities to achieve great success in their live if they have access to the appropriate learning method, which is suitable for them.

Revised Manuscript Received on June 22, 2019.

Rosmayati Mohemad, School of Informatics and Applied Mathematics, Universiti Malaysia Terengganu, 21030 Kuala Nerus, Terengganu, Malaysia

Nur FadilaAkma Mamat, School of Informatics and Applied Mathematics, Universiti Malaysia Terengganu, 21030 Kuala Nerus, Terengganu, Malaysia

Noor MaizuraMohamad Noor, School of Informatics and Applied Mathematics, Universiti Malaysia Terengganu, 21030 Kuala Nerus, Terengganu, Malaysia

ArifahChe Alhadi, School of Informatics and Applied Mathematics, Universiti Malaysia Terengganu, 21030 Kuala Nerus, Terengganu, Malaysia 


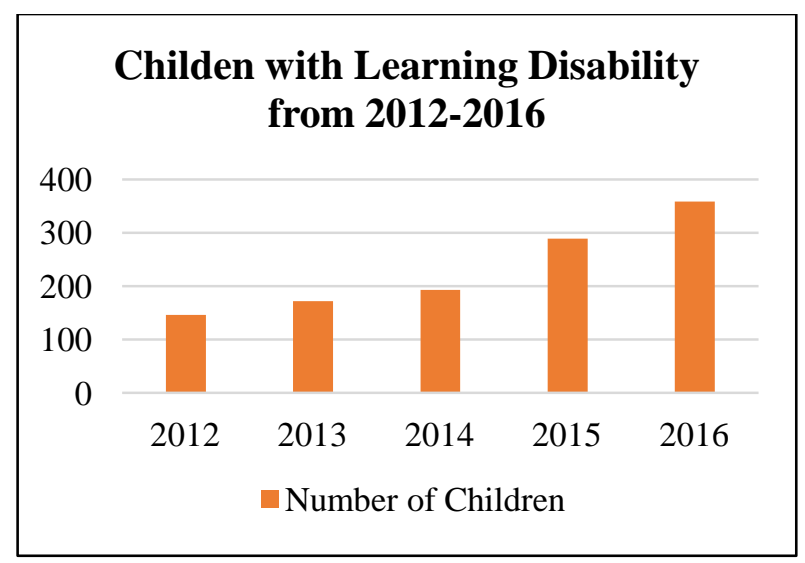

Fig. 1 Number of children with learning disability in Malaysia[11]

Early identification of children who may at risk of having difficulties in learning is crucial in order to assist them in overcoming barriers to learn. As the consequences, this will helps to prevent the growth of child with academic failure, lower motivation, greater frustration, distress, school dropout, and peers rejection [12], [13]. This process, however is very labour intensive, time-consuming and complex as it bounds to a comprehensive clinical review of the individual's developmental, medical, educational, and family history, test scores and teacher observations, and response to academic interventions [14]. In addition, it also relies on the diverse set of approaches, knowledge and experience of an expert. Therefore, some computerized support systems such as Smart Lexics[15], i-Dyslex[16][17], Mississippi Dyslexia Screener [18], DycScreen[19], Dytective[20], Dyslexia Quest [21], DysdTool[22], Computerized Handwriting Assessment[23], Handwriting movement fluency [24], Computer-based Screening Dyscalculia [25] have been developed in the area of specific learning disabilities to overcome the restrictions. However, these systems more focused to identify children or student with one specific type of learning disability. As far as we are concern, not much attention has been given to develop a computer-based support systems that can support the parents and untrained teachers in two main tasks; 1) early identification of children with three types of specific learning disabilities including dyslexia, dysgraphia and dyscalculia, and 2) providing information on both intervention and rehabilitation actions that can be undertaken based on the identified learning disability. Both tasks are vital so that parents and teachers will be aware of their children's academic and social development, and they will at least, know what to do if they find that their child encounters any of the learning disabilities problems. Therefore, a computer-based prototype for early identification of children with specific learning disabilities using ontology (e-SLD) is developed as one of the alternative approach to assist early identification of such special children and recommendations of appropriate intervention and rehabilitation actions based on the identification. Theprototype is important because it helps to intensify the alertness among people directly and indirectly. It is however not intended to replace expert's clinical diagnoses.

This paper is an extension work from Rosmayati et. al [26], whereby the evaluation of e-SLD in terms of its usability will further discuss here. The rest of the paper is organized as follows. Section 2 presentsthe state-of-the-art of current computerized tools for screening and recommendation of appropriate educational activity in specific learning disabilities environment. Meanwhile, the subsequent section outlines the overall frameworkof the research methodology. The e-SLD prototype development and evaluation of the developed prototype are discussed in Section 4. Finally, the last section concludes with a summary of this paper and future research directions.

\section{RELATED WORK}

There are ample of computer-based support systemsthat have been developed to early screening of children who might at risk of having specific learning disabilities. These systems adopted various technological approach such as web-based, interactive multimedia, game-based, artificial neural networks and image recognition as summarized in Table 1.

Table. 1 Summary of Computer-based Support Systems in Specific Learning Disabilities

\begin{tabular}{|c|c|c|c|c|c|}
\hline \multirow{4}{*}{ Computerized Tool } & \multirow{4}{*}{$\begin{array}{l}\text { Technological } \\
\text { Approach }\end{array}$} & \multirow{4}{*}{ Target User } & \multirow{4}{*}{ Screening } & \multicolumn{2}{|c|}{ Recommendation Activity } \\
\hline & & & & & Teaching \\
\hline & & & & Rehabilitation & $\&$ \\
\hline & & & & & Learning \\
\hline Smart Lexic[15] & $\begin{array}{l}\text { Interactive } \\
\text { multimedia }\end{array}$ & Dyslexic children & Yes & None & None \\
\hline iDyslex[16][17] & $\begin{array}{l}\text { Interactive } \\
\text { multimedia }\end{array}$ & Dyslexic children & Yes & None & None \\
\hline
\end{tabular}

Naïve Bayes, J48 and

Bayes Net

Mississippi Dyslexia Web-based

Screener [18]

DycScreen[19] Web-based

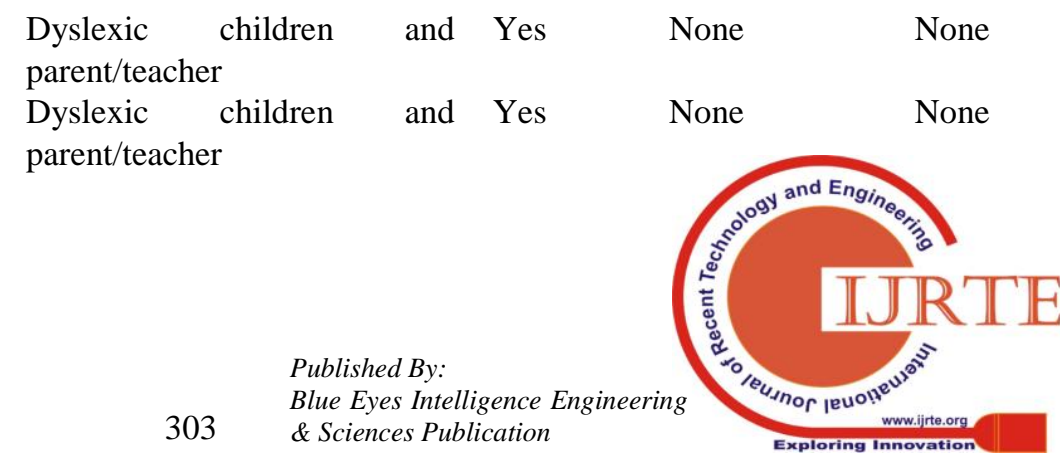




\begin{tabular}{|c|c|c|c|c|c|}
\hline Dytective[20] & Web-based game & $\begin{array}{l}\text { Dyslexic children and } \\
\text { parent/teacher }\end{array}$ & Yes & None & None \\
\hline Dyslexia Quest [21] & Game-based & $\begin{array}{l}\text { Dyslexic children and } \\
\text { parent/teacher }\end{array}$ & Yes & None & None \\
\hline DysdTool[22] & $\begin{array}{l}\text { Artificial } \\
\text { networks }\end{array}$ & Dyslexic children & Yes & None & None \\
\hline $\begin{array}{l}\text { Computerized } \\
\text { Handwriting } \\
\text { Assessment [23] }\end{array}$ & Image recognition & $\begin{array}{l}\text { Dysgraphia } \\
\text { occupational } \\
\text { psychologist }\end{array}$ & Yes & None & None \\
\hline $\begin{array}{l}\text { Handwriting } \\
\text { movement fluency } \\
{[24]}\end{array}$ & Image recognition & $\begin{array}{l}\text { Dysgraphia } \\
\text { occupational } \\
\text { psychologist }\end{array}$ & Yes & None & None \\
\hline $\begin{array}{l}\text { Computer-based } \\
\text { Screening } \\
\text { Dyscalculia [25] }\end{array}$ & $\begin{array}{l}\text { Standalone } \\
\text { computer-based }\end{array}$ & Dyscalculia children & Yes & None & None \\
\hline $\begin{array}{l}\text { Intelligent Tutoring } \\
\text { System [27] }\end{array}$ & $\begin{array}{l}\text { Adaptive } \\
\text { classification }\end{array}$ & $\begin{array}{l}\text { Dyscalculia } \\
\text { occupational } \\
\text { psychologist }\end{array}$ & Yes & None & None \\
\hline Askisi[28] & Web-based & $\begin{array}{l}\text { Learning disabilities children } \\
\text { and parent/teacher }\end{array}$ & Yes & None & None \\
\hline Yalu[29] & $\begin{array}{l}\text { Web-based } \\
\text { game }\end{array}$ & $\begin{array}{l}\text { Learning disabilities children } \\
\text { and parent/teacher }\end{array}$ & Yes & None & None \\
\hline MyLexics[30] & $\begin{array}{l}\text { Interactive } \\
\text { multimedia }\end{array}$ & Dyslexic children & No & None & Yes \\
\hline E-Z-Dyslexia [31] & Interactive & Dyslexic children & No & None & Yes \\
\hline
\end{tabular}

Smart Lexics[15] and i-Dyslex[16] are interactive multimedia computer-based screening tools, which were developed for early identification of dyslexic student. Both tools employed multimedia elements, where during the screening process, each children who might at risk of having dyslexia is required to solve some questions interactively. Further research in iDyslex has applied data mining techniques to classify either the potential children is dyslexic or not based on the data collected during the screening [17]. Besides that, several dyslexia screening tools such Mississippi Dyslexia Screener[18] and DycScreen[19] have implemented web-based approach. Both tools consists of several screening test modules pertaining to the dyslexia symptoms, in which potential dyslexic children are required to take part online. Meanwhile, another computer-based applications such as Dytective[20] and Dyslexia Quest [21]adopted game-based approach to test children's cognitive leaning ability in terms of verbal comprehension, perceptual reasoning, working memory and speed of processing. At the same time, research that has been carried out by Costa et al. [22] applied neural networks technique to screen school-aged children with dyslexia.

Furthermore, several researches has been done to early identify potential children with dysgraphia based on the handwriting assessment. For instance, a computerized handwriting assessments tool that has been developed by Chea et al. [23] implemented image recognition algorithm to identify errors based on stroke sequences and directions of the writings when the children is dynamically forming an alphabet. Another research has been done by Danna et al.[24]where they used Signal-to-Noise velocity peaks difference to evaluate handwriting movement fluency. It detects abnormal speed for cursive handwriting. Meanwhile several tools were proposed for screening children who might at risk of struggling with dyscalculia, to name a few such as Computer-based Screening Dyscalculia [25] and Intelligent Tutoring System [27]. Stealth assessment has been used to automatic detect children with dyscalculia while they are training with the Intelligent Tutoring System. Even though these tools have shown to be conducive alternative in early identification, but these tools however only were designed for handling one specific type of learning disability at a time. Only a few tools are available for screening learning disabilities children that includes all together three types of specific learning disabilities such as Askisi[28] and Yalu[29]. Nevertheless, these tools merely focused on the early identification process. Therefore, there are vital needs for the emergence of support system which is not only capable to do the early identification but also able to provide the information (intervention and rehabilitation) about the children with the specific learning disabilities.

\section{FRAMEWORK OF RESEARCH METHODOLOGY}

In this research, the overall research methodology as depicted in Figure 2 consists of two main phases; 1) software development life cycle and 2) usability testing. Both phases are explained in details for the next subsections. 


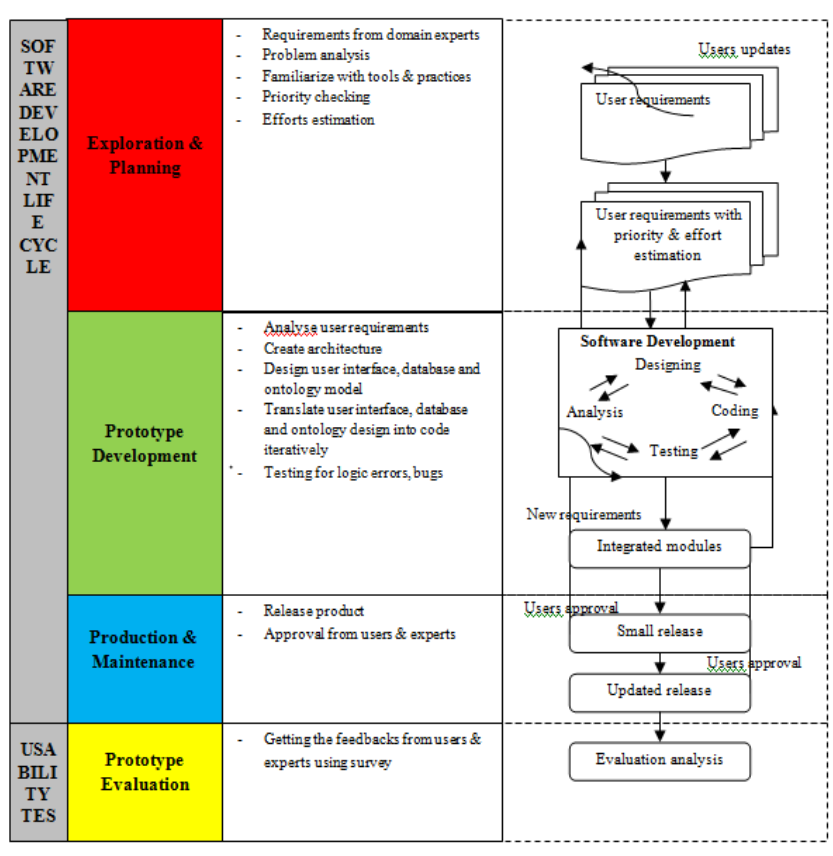

Fig. 2 The framework of development system methodology

\section{Phase 1: Software Development Life Cycle}

In this phase, the process of developing e-SLD prototype is carried out based on Agile software development method using extreme programming approach, in which it is based on the combination of iterative and incremental process models. Agile method mainly depend on people's expertise rather than documented process. Some of agile principles are to deliver something that useful, encourage collaboration and technical excellence. As depicted in Figure 2, this phase is divided into three sub phases including exploration and planning, prototype development and production and maintenance. The following is the details explanation of each sub phase.

\section{The exploration and planning}

In this sub phase, the objectives are discussed and scopes for system review are developed. This is to ensure the application of this system achieved. Data collection and analysis on the specific domain are conducted to identify problems that occur during the process. The data and information are collected through the internet, articles and related documents. Meanwhile, the functional requirements are collected from domain experts in special education such as medical practitioners, occupational therapist and special education teachers. A series of meetings and interviews are conducted with the domain experts in order to obtain consensus requirements that need to be included in the first release. Based on the requirements obtained, development process is divided into several small number of modules. Information also can be obtained from brainstorming the whole function of the system. Every details of the process that conducted is discussed in an open-ended way before implementation. Meanwhile, tools such as Net Beans IDE 8.2, My SQL and Top Braid Composer are familiarized. These three tools are essential to build e-SLD prototype. In addition, the technology possibilities for supporting the development of prototype are explored as well.

Planning sub phase sets the priority order for the user requirements obtained in the previous phase and an agreement of the contents of the first small release is made. Even the first release of plan is precise, the plan will be reviewed regularly to make sure the planning meets the aim of the prototype development. Estimation amount of efforts and schedule for each module are also determined. It aims to ensure that the resulting products will produce high quality system that meets the user requirements and to ensure that the system is completed within the prescribed period.

\section{Prototype Development}

The proses in this sub phase contains several cycles of the software development for each module before the first release. Each cycle of software development includes several iterative steps such as analysis, design, coding and testing. The first iteration is to establish the system architecture of the whole modules as a baseline structure. This is achieved by combining the requirements identified. In the analysis, details study of each module is done. Functions and users of the system in each of the modules is analysed and identified. User interfaces, database and ontology model are designed for each module. Extreme programming focuses on delivering good work in every iteration. It uses a continuous process to improved design of the system. User interfaces are designed based on the suitability of the types of users and main focused area of the current functionality of the system. Database is designed to manipulate the data. Ontology model is also designed. Coding is an implementation step that serves to translate design representation into programming language. Extreme programming follows a common coding standard so that all the code in the system understandable by others programmer. The last iterative step is testing where each developed module is tested for any logic errors and bugs. If any errors or bugs are detected, they will be removed in the next cycle. This test provides invaluable support as the software design is improved. During software development process, requirements from new user come and the cycle plan should be adjusted according to the updated data. At the end of the last cycle of the last module, the whole modules are integrated into a system and is ready for production.

\section{The production and maintenance}

Pilot testing and checking of the system performance are required before it can be released to the user. At this phase, feedbacks from users are taken into account. Here, new changes may still be discovered and the previous phases need to be revisited.

\section{Phase 2: Usability Testing Survey}

In this phase, e-SLD prototype is evaluated by testing its usability. The usability testing is done with a group of users including domain experts (medical practitioners, occupational therapist, special education teacher) and public users (parents, untrained teachers). The purposes of this testing is to identify any usability problem in e-SLD prototype and to determine users satisfaction with the developed prototype. 
Therefore, it is conducted using survey to collect the qualitative data. Before that, users are recruited to test all the functionalities of e-SLD prototype. Then, each of the user is required to answer a set of questionnaire by giving the feedbacks on the usability of prototype to complete a particular task, and how the correctness and consistency of the given output from the prototype are affected by the use of the ontology.

\section{RESULTS AND DISCUSSIONS}

\section{Prototype design and development}

A prototype of e-SLD has been developed, in which it aims to support target communities such as medical practitioners, occupational therapist, parents and teachers for early recognizing their children or students that are struggling with specific learning disabilities. The prototype also intends to guide parents and teachers especially on inhome practices on how to educate the children by recommending suitable educational activities (intervention and rehabilitation) based on the identified learning disabilities. It is a web-based prototype and ontology model is adopted for screening and recommending processes by reasoning inference rules. However, the discussion on the ontology model is beyond the scope of this paper.

In summary, Figure 3 to Figure 6 shows the snapshots of e-SLD, in which it consists of four main modules; 1) authentication, 2) screening, 3) recommendation and 4) report. The users of the system have to be registered before they can $\log$ into the application. Simple information is required to be completed in the registration form as shown in Figure 3 to secure an authenticated identification. Once the users login into the application, they are allowed to do the screening process. The user operating the screening module as in Figure 4 by answering a set of questions based on the children's progress. The data is sent to the database and ontology model is inferred to analyse the data. After analysis, the problems of their child could be identified and recommendations of activities to improve the developments were suggested in recommendation module as depicted in Figure 5. After completion of all steps, a printable report was produced as presented in Figure 6. Details discussion of e-SLD architecture and prototype has been done in Rosmayati et. al [27].

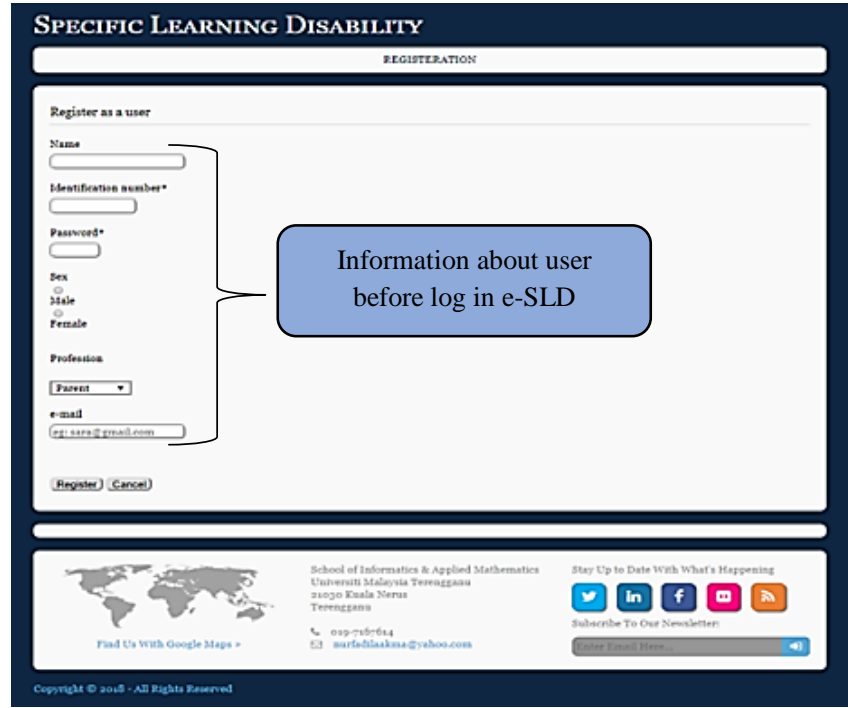

Fig. 3 Authentication module

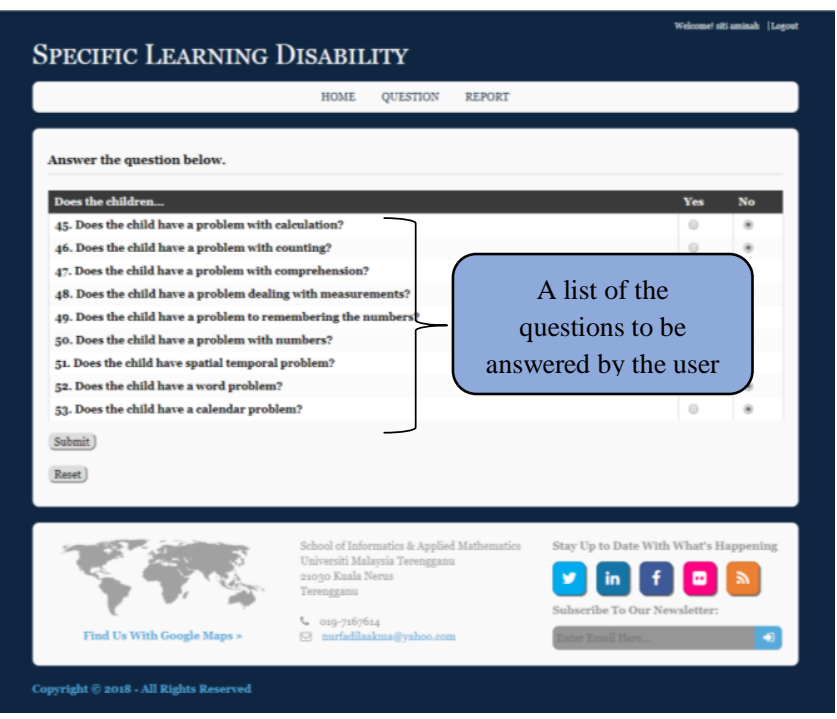

Fig. 4 Screening module

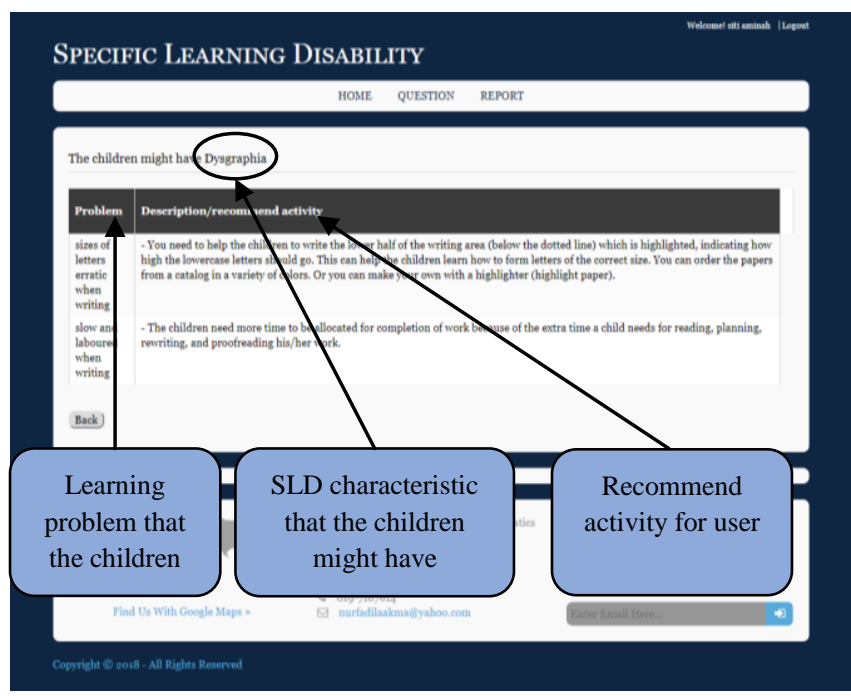

Fig. 5 Recommendation module

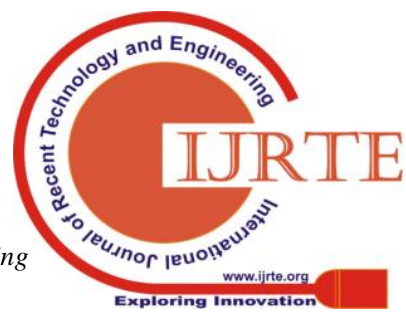




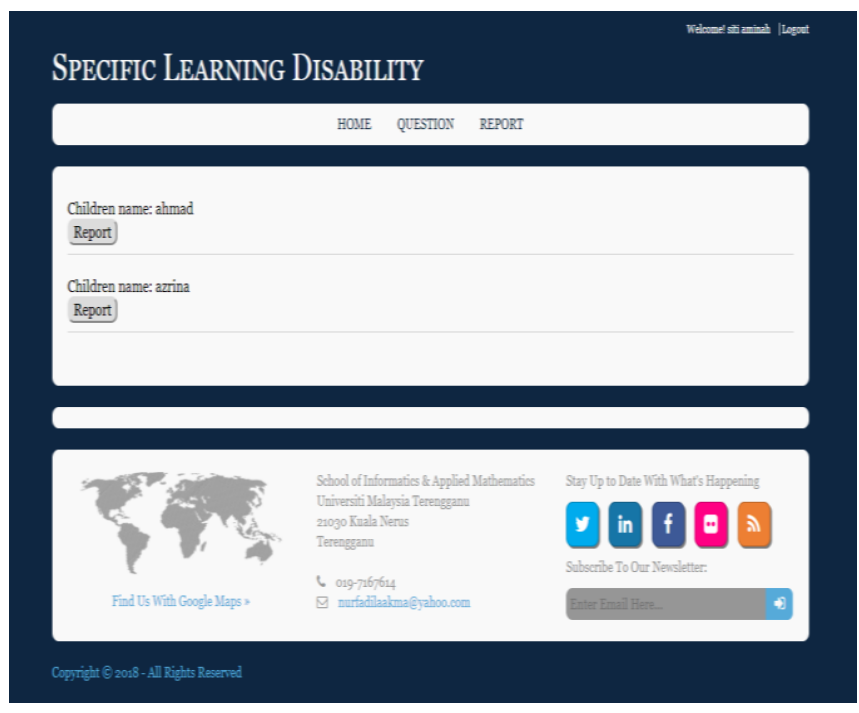

on the system's applications with the users. Before the trial start, the respondents were selected and given a letter of appointment. The respondents were the target group of medical practitioners, special education teachers and occupational therapist. Each respondent was assigned to carry out the e-SLD and upon completing he/she has to answer a set of questionnaires as given in Table 2 regarding the usefulness of the system.

Fig. 6 Report module

\section{Evaluate the usability of e-SLD}

The usability of the e-SLD is measured by conducting a trial

Table. 2 A Set of Questionnaires for Usability Testing

\begin{tabular}{|l|l|l|}
\hline Factors & Questionnaire code & Questionnaire \\
\hline PE & Q1 & I can effectively complete my work quickly using this e-SLD \\
\hline PE & Q2 & I am able to complete my work quickly using this e-SLD \\
\hline PE & Q4 & I believe I became productive quickly using this e-SLD \\
\hline PE & Q5 & This e-SLD is a fair way to identify a child's problem. \\
\hline PE & Q6 & The activity is reasonable for the described problem. \\
\hline PE & Q7 & The activity provides a suitable way to handle the child's problems. \\
\hline PE & Q9 & e-SLD provides you the information for easy decision making. \\
\hline PE & Q10 & $\begin{array}{l}\text { e-SLD improves the quality of decision-making to determine suitable activities } \\
\text { for children. }\end{array}$ \\
\hline PE & Q11 & $\begin{array}{l}\text { e-LD provides the right decision in determining suitable activities for children } \\
\text { with SLD. }\end{array}$ \\
\hline PE & Q12 & e-SLD provides the same answer as the expert's answer. \\
\hline PE & $\begin{array}{l}\text { e-LD increases confidence in the provision of assessment to determine suitable } \\
\text { activities for children that have a problem in SLD. }\end{array}$ \\
\hline PE & Q13 & $\begin{array}{l}\text { e-SLD reduces the injustice in making decisions to determine suitable activities } \\
\text { for children that have a problem in SLD. }\end{array}$ \\
\hline EE & Q14 & This e-SLD would be an acceptable activity strategy for a child's problems \\
\hline EE & Q15 & $\begin{array}{l}\text { e-SLD is easy to use to get information on a suitable activity for children with } \\
\text { SLD. }\end{array}$ \\
\hline SI & Q16 & I would suggest the use of this e-SLD in schools and clinics. \\
\hline SI & Q17 & This e-SLD is appropriate for children between 4-7 years old. \\
\hline SI & Q19 & SLD system helps teachers and parent to do early screening for their children. \\
\hline SI & Q20 & Overall, would this system be beneficial for the children. \\
\hline SI & Overall, would this system be beneficial for teachers and parents. \\
\hline FC & Is there any tools for classify children that have a problem in SLD? \\
\hline
\end{tabular}

The characteristics of the question are based on Unified Theory of Acceptance and Use of Technology (UTAUT) model that has been done by Venkatesh et al.[33]. UTAUT states that consumer acceptance and use of technology are explained by four factors, namely performance expectancy (PE), effort expectancy (EE), social influence (SI) and facilitating condition (FC) that are the direct determinants of behavioral intention and behavioral use.PE can be categorized in two functions based on the performance and the usefulness of the system. Venkatesh et al.[33] integrate five concepts from different model that is usefulness,

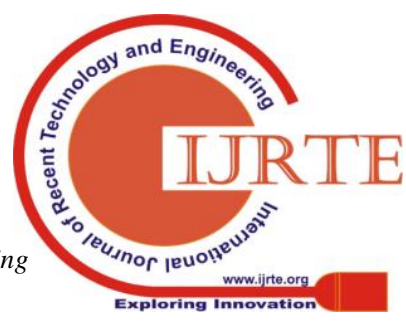


extrinsic motivation, job-fit, relative advantage and outcome expectation. Meanwhile, EE mainly assess the user's understandability of the system. SI assesses the user's acceptability to the system. Whilst, FC focus more on existing tools or system that can be used in related organization. Table 3 shows the analysis of respondents' feedbacks for the four factors of UTAUT.

Table. 3 The Analysis of Respondents' Feedbacks for the Usability of e-SLD

\begin{tabular}{|c|c|c|}
\hline Factors & Questions & Percentage \\
\hline \multirow[t]{12}{*}{ Performance Expectancy (PE) } & Q1 & $80 \%$ \\
\hline & $\mathrm{Q} 2$ & $80 \%$ \\
\hline & Q3 & $80 \%$ \\
\hline & Q4 & $60 \%$ \\
\hline & Q5 & $68 \%$ \\
\hline & Q6 & $60 \%$ \\
\hline & Q7 & $64 \%$ \\
\hline & $\mathrm{Q} 8$ & $60 \%$ \\
\hline & Q9 & $75 \%$ \\
\hline & Q10 & $75 \%$ \\
\hline & Q11 & $64 \%$ \\
\hline & Q12 & $72 \%$ \\
\hline \multirow[t]{2}{*}{ Effort Expectancy (EE) } & Q13 & $76 \%$ \\
\hline & Q14 & $68 \%$ \\
\hline \multirow[t]{5}{*}{ Social Influences (SI) } & Q15 & $52 \%$ \\
\hline & Q16 & $72 \%$ \\
\hline & Q17 & $76 \%$ \\
\hline & Q18 & $68 \%$ \\
\hline & Q19 & $75 \%$ \\
\hline Facilitating Condition (FC) & Q20 & $72 \%$ \\
\hline
\end{tabular}

In average, about $70 \%$ of the respondents agreed with the system in terms of its performance expectancy. So, it can generally be concluded that this system was accepted by the users. The users believe e-SLD will help them to do their jobs better. Furthermore, e-SLD also considered to give positive impact to reduce time consuming, human resource and management. e-SLD also will help user to attain gains in performance. The user think that e-SLD as a new technology being more useful that the present method of screening. Meanwhile, in terms of effort expectancy, about $72 \%$ of the respondents agreed with the system in terms of the e-SLD's understandability. The results approves that the system was comprehended by the users. The users believe that content in e-SLD can be accepted by the user easily to help the user to make decision in process of screening and give suitable recommendation on the intervention and rehabilitation activities to be taken.

For the factor of social influence, about $68 \%$ of the respondents agreed with the system in terms of its behavioural intention in use and acceptance of e-SLD. An expert such as medical doctor, teachers and practitioners suggest that e-SLD can be used in their work place. They suggest e-SLD also suitable for children between four to seven years old. Parents and teachers can screening their children or student that have a learning problem to identify exactly the specific difficulty that they experienced. In terms of facilitating condition, there is around $72 \%$ of the respondents agreed that there is a tool to screening and recommending suitable activity of SLD children. The tools such as questionnaire that specific to verify the learning problem for the children and some test that mostly clinical and practitioners applied at their school or clinical. However they don't have database to storethe information for the purpose of decision-making.

In summary, the evaluation result obtained from the survey indicates the tool acceptance in terms of the usability of the e-SLD for early screening student that at risk of having dyslexia, dysgraphia or dyscalculia, and suitable educational activities.

\section{CONCLUSION}

The development of e-SLD contributes as an alternative for assisting general users such as parents and untrained teachers for the early screening of their learning problem's children. From the reviews of the past research, there are no devices or tools providing the information in handling these types of children, which is directly accessible to parents or teachers. Therefore, this prototype is beneficial for parents and teachers as the guide source on in-home practices for conducting early intervention and rehabilitation activities with their child as part of the efforts to beat their child's learning barriers. The used of tools may also reduce manual human efforts, since the clinical diagnosis which is currently can only be done by medical practitioners, the early checking and therapies can now be done at home.

However, in current e-SLD, users need to deal with many questions before the outputs are produced. So the process is tedious and also time-consuming. In the future research direction, the e-SLD can be improved, 
in which instead of answering the bunch of questions, the users just need to input some natural language-based queries of the learning problem's symptoms (e.g. "my child always found difficulty in calculation") and ontology model will be able to extract the keyword and infer rules to identify the problems. This future research can be explored further in the field of Natural Language Processing (NLP).

\section{ACKNOWLEDGEMENT}

This research is supported by the Malaysian Ministry of Higher Education, Fundamental Research Grant Scheme (FRGS) vote 59395.

\section{REFERENCES}

1. B. Saleena and S. K. Srivatsa, "Using concept similarity in cross ontology for adaptive e-Learning systems," J. King Saud Univ. Comput. Inf. Sci., 2015.

2. L. Jiang, C. Zhao, and H. Wei, "The development of ontology-based course for computer networks," in Proceedings - International Conference on Computer Science and Software Engineering, CSSE 2008, 2008.

3. Y. a Alsultanny, "e-Learning System Overview based on Semantic Web," System, vol. 4, no. 2, pp. 111-118, 2006.

4. B. C. Trolley, H. S. Haas, and D. C. Patti, "Chapter 2: Special Education Terminology and Disability Categories," in The School Counsellor's Guide to Special Education, 2009.

5. V. V Mogasale, V. D. Patil, N. M. Patil, and V. Mogasale, "Prevalence of specific learning disabilities among primary school children in a south Indian city," Indian J. Pediatr., 2012.

6. S. Bandla, G. D. Mandadi, and A. Bhogaraju, "Specific Learning Disabilities and Psychiatric Comorbidities in School Children in South India," Indian J. Psychol. Med., vol. 39, no. 1, pp. 76-82, 2017.

7. H. Habib, "Awareness about Special Education in Hyderabad," vol. 4, no. 5, pp. 1296-1300, 2015

8. B. H. Lim and K. H. Chia, "From Teachers and Family To Community: What Support Is Available for Our Children With," pp 46-58, 2017.

9. K. Kakabaraee, A. A. Arjmandnia, and G. A. Afrooz, "The Study of Awareness and Capability of Primary School Teachers in Identifying Students with Learning Disability in the Province of Kermanshah," Procedia - Soc. Behav. Sci., vol. 46, pp. 2615-2619, 2012.

10. Garry, H. Jean, and M. Atkinson, Controversial Issues in Special Education, Second Edi. Cambridge: David Fulton Publisher, 2013.

11. J. Hernández, G. Mousalli, and F. Rivas, "Expert System for the Diagnosis of Learning Difficulties in Children's Basic Education," in The 8th WSEAS Int. Conf. on Applied Computer and Applied Computational Science (ACACOS '09), 2009, pp. 67-71.

12. Kementerian Pendidikan Malaysia, "Data Pendidikan Khas," p. 34, 2016.

13. E. G. Willcutt, R. Boada, M. W. Riddle, N. Chhabildas, J. C. DeFries, and B. F. Pennington, "Colorado Learning Difficulties Questionnaire:Validation of a parent-report screening measure," Psychol. Assess., vol. 23, no. 3, pp. 778-791, 2011.

14. C. Cortiles and S. H. Horowitz, "The state of learning disabilities: Facts, trends and emerging Issues," Natl. Cent. Learn. Disabil., vol. 3, pp. 1-52, 2014.

15. S. Fortes, C. S. Paula, M. C. Oliveira, I. A. Bordin, J. de Jesus Mari, and L. A. Rohde, "A cross-sectional study to assess the prevalence of DSM-5 specific learning disorders in representative school samples from the second to sixth grade in Brazil," Eur. Child Adolesc. Psychiatry, vol. 25, no. 2, pp. 195-207, 2016.
16. H. M. Ekhsan et al., "The implementation of interactive multimedia in early screening of dyslexia," in ICIMTR 2012 - 2012 International Conference on Innovation, Management and Technology Research, 2012, pp. 566-569.

17. W. M. W. Isa, S. N. W. Shamsuddin, N. S. F. N. Mat, M. Makhtar, F. S. Mohamad, and R. Husain, "Heuristic Evaluation Of i-Dyslex Tool for Dyslexia Screening," J. Telecommun. Electron. Comput. Eng., vol. 9, no. 2-4, pp. 15-19, 2017.

18. S. N. W. Shamsuddin, N. S. F. N. Mat, M. Makhtar, and W. M. W. Isa, "Classification Techniques for Early Detection of Dyslexia Using Computer-Based Screening Test," World Appl. Sci. J., vol. 35, no. 10, pp. 2108-2112, 2017.

19. E. Blackwell, N. Durkee, P. Flynn, and S. B. Blackley, "The Mississippi Dyslexia Screener: An Inter-Scorer Reliability Study," in American Speech-Language- Hearing Association Annual Convention, 2014, p. 1.

20. N. Che Pee, P. H. Leong, M. A. Othman, H. A. Sulaiman, M. F. I. Othman, and Y. A. Rahim, "DycScreen-Cross-Platform Dyslexia Screening Test for Malaysian Children Through Hybrid Applications BT - Advanced Computer and Communication Engineering Technology," 2016, pp. 1083-1091.

21. L. Rello, K. Williams, A. Ali, N. C. White, and J. P. Bigham, "Dytective: Towards Detecting Dyslexia Across Languages Using an Online Game," in Proceedings of the 13th Web for All Conference, 2016, p. 29:1--29:4.

22. B. Carbol, "Research Brief: Use of The Dyslexia Quest App as a Screening Tool," 2014.

23. M. Costa et al., "A computational approach for screening dyslexia," in Proceedings of CBMS 2013 - 26th IEEE International Symposium on Computer-Based Medical Systems, 2013, no. Figure 1, pp. 565-566.

24. N. C. Chea, E. S. L. Ming, P. I. Khalid, and Y. C. Fai, "Algorithm for Identifying Writing Stroke and Direction," 2012 Fourth Int. Conf. Comput. Intell. Model. Simul., pp. 94-98, Sep. 2012.

25. J. J. Danna, V. Paz-Villagran, J.-L. Velay, V. Paz-Villagrán, and J.-L. Velay, "Signal-to-Noise velocity peaks difference: A new method for evaluating the handwriting movement fluency in children with dysgraphia," Res. Dev. Disabil., vol. 34, no. 12, pp. 4375-4384, Dec. 2013.

26. B. Cangoz, A. Altun, S. Olkun, and F. Kacar, "Computer Based Screening Dyscalculia: Cognitive and Neuropsychological Correlates," Turkish Online J. Educ. Technol. - TOJET, vol. 12, no. 3, pp. 33-38, 2013.

27. R. Mohemad, N. F. A. Mamat, N. M. M. Noor, and A. C. Alhadi, "ICT as a Tool for Screening Student with Specific Learning Disabilities," in 10th International Conference on Language, Education, and Innovation, 2018, pp. 113-123.

28. S. Klingler et al., "Stealth Assessment in ITS - A Study for Developmental Dyscalculia BT - Intelligent Tutoring Systems," 2016, pp. 79-89.

29. N. C. Zygouris et al., "Learning Difficulties Screening Web Application," in Proceedings of International Conference on Interactive Collaborative Learning (ICL), 2015, no. September, pp. 650-654.

30. T. C. P. Kularathna, L. C. Kuruppuarachchi, W. M. S. S. Wijekoon, W. A. M. Kulamini, R. N. Samarasingha, and D. Tharanga, "Yalu: Computer Game Based Solution to Screen Learning Disabilities in Kids," in 4th National Conference on Technology \& Management (NCTM), 2014, pp. 1-6.

31. 31. M. Haziq, L. Abdullah, S. Hisham, and S. Parumo, "MyLexics: An Assistive Courseware for Dyslexic Children to Learn Basic Malay Language MyLexics : Courseware Modules," no. 95, pp. 3-9, 2009.

32. E. M. M. Mahidin, "Preliminary Courseware Conceptual Model for Dyslexic Children,” Int. J. Innov. Educ. Res., vol. 2, no. 08, pp. 54-60, 2014

33. Viswanath Venkatesh, Michael G. Morris, Gordon B. Davis, and Fred D. Davis, "User acceptance of information technology:TOWARD A UNIFIED VIEW1,” MIS Q. (MIS QUART), vol. 27, no. 3, pp. 425478, 2003. 